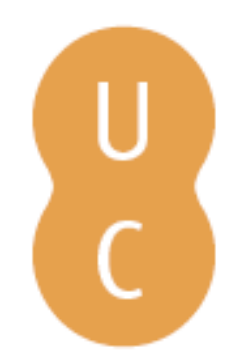

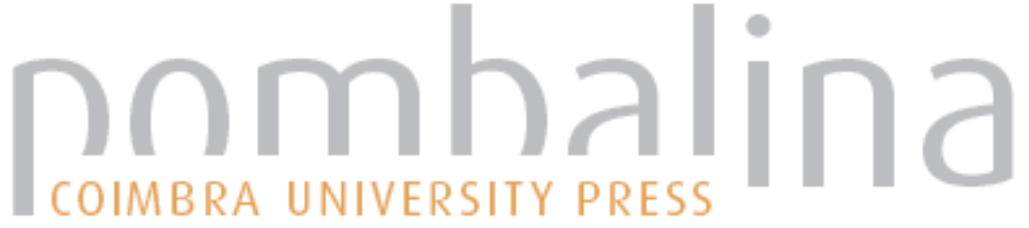

\section{Obstipação, encoprese e enurese}
Autor(es):
Oliva, Mónica
Publicado por: Imprensa da Universidade de Coimbra
URL persistente:
URI:http://hdl.handle.net/10316.2/43129
DOI:
DOl:https://doi.org/10.14195/978-989-26-1300-0_28

Accessed : $\quad$ 26-Apr-2023 14:15:12

A navegação consulta e descarregamento dos títulos inseridos nas Bibliotecas Digitais UC Digitalis, UC Pombalina e UC Impactum, pressupõem a aceitação plena e sem reservas dos Termos e Condições de Uso destas Bibliotecas Digitais, disponíveis em https://digitalis.uc.pt/pt-pt/termos.

Conforme exposto nos referidos Termos e Condições de Uso, o descarregamento de títulos de acesso restrito requer uma licença válida de autorização devendo o utilizador aceder ao(s) documento(s) a partir de um endereço de IP da instituição detentora da supramencionada licença.

Ao utilizador é apenas permitido o descarregamento para uso pessoal, pelo que o emprego do(s) título(s) descarregado(s) para outro fim, designadamente comercial, carece de autorização do respetivo autor ou editor da obra.

Na medida em que todas as obras da UC Digitalis se encontram protegidas pelo Código do Direito de Autor e Direitos Conexos e demais legislação aplicável, toda a cópia, parcial ou total, deste documento, nos casos em que é legalmente admitida, deverá conter ou fazer-se acompanhar por este aviso. 


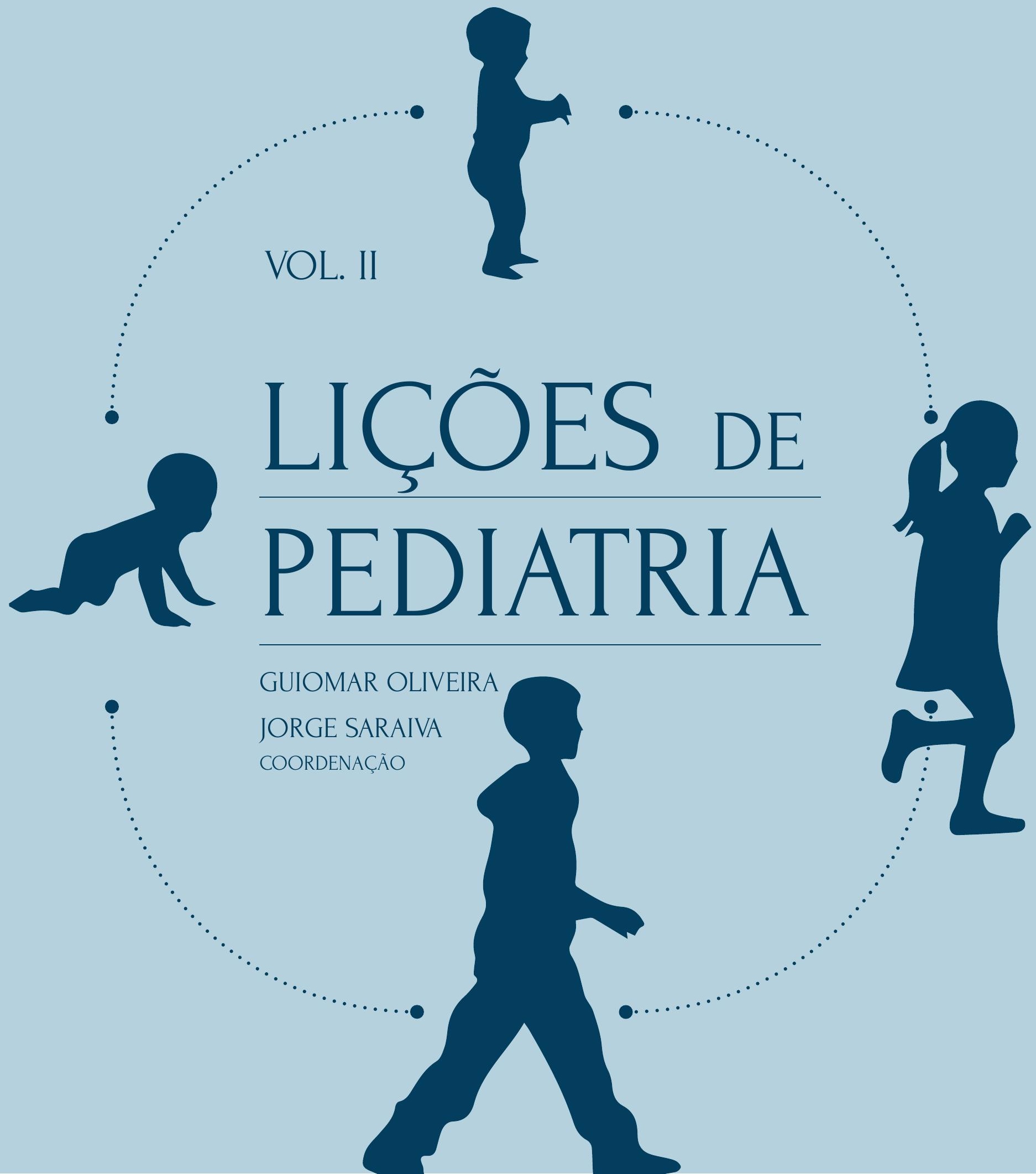


Capítulo 28.

Obstipação, encoprese e enurese
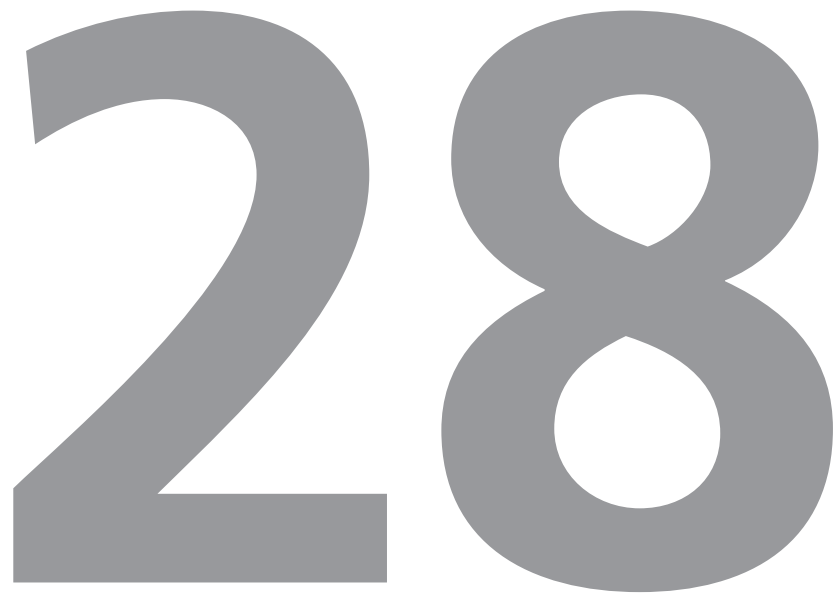

\section{Mónica Oliva}




\subsection{OBSTIPAÇÃO E ENCOPRESE}

\subsubsection{Definições e epidemiologia}

A obstipação é uma doença muito prevalente em idade pediátrica, mas frequentemente subdiagnosticada e tratada de forma pouco eficaz. A sua orientação constitui um desafio não só para o médico mas também para o doente e sua família.

A definição de obstipação deve ter em conta não só as características das fezes (consistência, frequência das dejeções) mas também sinais/sintomas associados tais como dor, retenção e perda de fezes (encoprese ou incontinência fecal).

Segundo os critérios de Roma IV, o diagnóstico de obstipação funcional ou seja sem doença orgânica subjacente, implica a presença de dois ou mais dos seguintes parâmetros assinalados no quadro 1.

Define-se encoprese ou incontinência fecal como a eliminação involuntária ou voluntária de fezes em locais inapropriados (roupa interior, chão,...), em crianças com idade cronológica ou mental de pelo menos quatro anos e que não resulta da utilização de fármacos (i.e. laxantes) ou outra doença que não a obstipação. O tempo necessário para se fazer o diagnóstico difere consoante os critérios utilizados, pelo menos um mês (Roma IV) ou três ou mais meses (Diagnostic and Statistical Manual of Mental Disorders 5 - DMS 5).

Ao contrário da obstipação na qual não parece haver predomínio de género em idade pediátrica, a encoprese é mais frequente nos rapazes.
Presença de dois ou mais dos seguintes critérios, pelo menos durante um mês:

1. $\leq$ duas dejeções / semana (na sanita se idade mental $\geq 4$ anos);

2. retenção fecal excessiva ou posturas retentivas;

3. dejeções dolorosas ou difíceis;

4. fezes de grande diâmetro;

5. elevado volume fecal no reto;

Após controlo do esfíncter, incluir também:

6. $\geq$ um episódio / semana de incontinência fecal;

7. fezes de diâmetro elevado, passiveis de obstruir a sanita.

Quadro 1. Critérios do diagnóstico de obstipação funcional - Roma IV (2016).

O pico de incidência da obstipação ocorre entre os dois e os quatro anos, idade do treino do controlo do esfincter anal.

\subsubsection{Etiologia}

A grande maioria das obstipações (90 a 95\% dos casos após o período neonatal) é de natureza funcional ou seja sem causa orgânica subjacente.

As idades-chave para o estabelecimento de obstipação funcional na criança são a idade do treino do controlo do esfíncter anal, a idade escolar e, mais raramente, na diversificação alimentar 
ou na substituição do leite materno por leite de fórmula.

A idade de controlo do esfíncter anal e de treino da defecação varia de criança para criança. Aos quatro anos, 98\% das crianças apresenta esta competência pois o desenvolvimento neuro-psico-social atingido, permite-Ihes ter a perceção da sensação de defecação, a compreensão da pressão social para que a dejeção ocorra no local apropriado, a ativação dos músculos voluntários envolvidos na continência fecal e a procura do bacio/sanita.

Uma má experiência no momento de retirar a fralda pode determinar obstipação crónica e incontinência fecal subsequente. É importante aguardar pela maturação de cada criança e que este treino decorra num ambiente tolerante e construtivo.

As raras causas orgânicas de obstipação poderão ser: neuropáticas (doença de Hirschsprung), anatómicas (ânus anterior), endócrinas (hipotiroidismo), imunológicas (doença celíaca, alergia às proteínas do leite de vaca), metabólicas (hipercalcémia), entre outros exemplos.

Cerca de 90\% dos casos de incontinência fecal são secundários a obstipação funcional com impactação fecal. Nesta situação as fezes eliminadas são habitualmente mais moles e ocorrem habitualmente durante o dia. Frequentemente, a criança mais velha sente-se envergonhada, evitando situações em que poderá ficar mais exposta como ir a acampamentos ou à escola. O impacte negativo causado depende do efeito que tem na autoestima da criança, do grau de ostracismo social por parte dos colegas e da atitude dos cuidadores (punição, rejeição,...). Este tipo de incontinência fecal resolve após tratamento da obstipação.

Nos restantes casos, verifica-se uma perda voluntária de fezes, sem retenção fecal. As fezes são de características normais, as perdas são intermitentes. Está frequentemente associada a distúrbios de oposição e desafio ou de conduta.

\subsubsection{Fisiopatologia}

Os clínicos devem estar familiarizados com a fisiopatologia da obstipação funcional, pois só assim poderão explicá-la à criança e aos pais etapa fundamental para aumentar a adesão ao tratamento.

O desencadeante mais frequente da obstipação é uma dejeção dolorosa que pode resultar de fezes muito duras ou de uma fissura anal. $\mathrm{Na}$ criança pequena, uma dejeção dolorosa no bacio ou na sanita leva frequentemente à evicção desses locais. Essa aversão pode ainda dever-se a um treino da defecação prematuro e/ou coercivo. Na criança mais velha verifica-se frequentemente indisponibilidade para defecar, ou por querer continuar a brincar, ou por recusa em utilizar casas-de-banho fora de casa.

O medo de defecar e o seu adiamento conduzem a retenção fecal voluntária, da qual resulta estagnação fecal mantida. Estas fezes sofrem reabsorção progressiva de água, adquirindo dimensões maiores e tornando-se cada vez mais duras. Neste ponto instala-se um ciclo vicioso que agrava a retenção fecal.

A distensão progressiva do reto e das suas terminações nervosas leva à perda da sensibilidade 


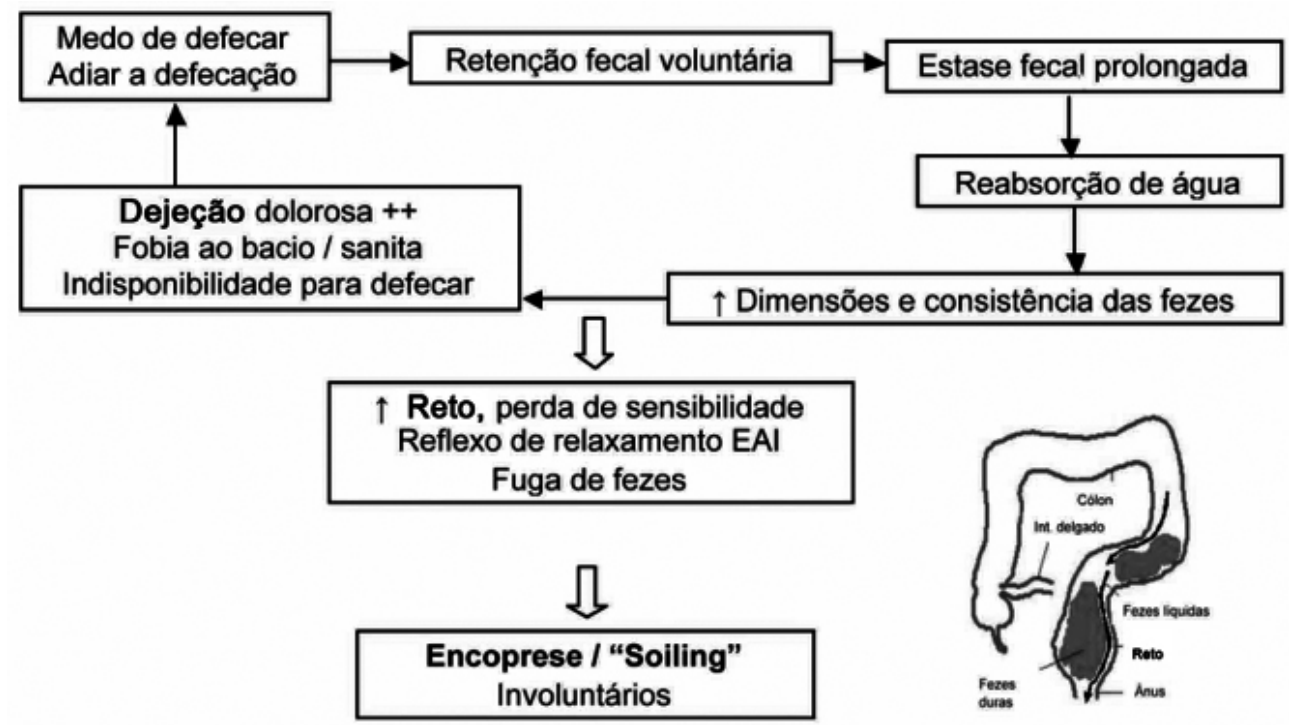

Figura 1. Fisiopatologia da obstipação funcional e encoprese. EAl - Esfincter anal interno. (adaptado de Obstipação e Incontinência Fecal na Criança. Saúde Infantil 2012; 34(1): 25-30)

defecatória. Como consequência, quando se dá o reflexo de relaxamento do esfíncter anal interno (em resposta às contrações retais), ocorre fuga involuntária de fezes. Habitualmente, são fezes mais recentes, pouco consistentes, que passam entre a parede retal e as fezes impactadas (figura 1). Alguns autores chamam "soiling" a esta perda involuntária de fezes líquidas que sujam a roupa interior.

É muito importante transmitir aos pais que a incontinência fecal no contexto de obstipação é involuntária, não devendo a criança ser culpabilizada.

\subsubsection{Diagnóstico}

Na grande maioria dos casos a história clínica permite diagnosticar uma obstipação funcional.
A pesquisa de sinais de alarme visa a exclusão de causas orgânicas.

Na anamnese, a idade atual da criança e de início das queixas são importantes uma vez que há faixas etárias consideradas de risco para o aparecimento de obstipação. O início no período neonatal é a favor de causa orgânica.

O padrão de dejeções, isto é, a frequência e o tipo de fezes (frequentemente volumosas ou em cíbalas) é importante, bem como a presença de retorragias. Na ausência de fissura anal, a presença de retorragias representa um sinal de alarme.

Os episódios de incontinência fecal devem ser bem caracterizados, em relação à sua frequência, tipo de fezes perdidas e ocorrência de episódios noturnos (sinal de alarme). Os pais devem ser questionados sobre possíveis comportamentos de retenção fecal, nos quais a criança habitualmente 
contrai as nádegas e o pavimento pélvico, faz hiperextensão dos membros inferiores, cruza-os alternadamente e adota outras posturas bizarras, fazendo-o frequentemente longe da vista dos adultos. Não é raro os pais interpretarem "soiling" como resultado de higiene insuficiente por parte da criança; outros interpretam-no como sendo diarreia.

Os principais sinais e sintomas acompanhantes da obstipação são: dor abdominal ou à defecação, distensão abdominal, anorexia, náuseas, vómitos (se ausência de dejeções há vários dias).

Nos antecedentes pessoais é necessário questionar sobre a eliminação de mecónio. Perante um atraso (após as primeiras 48 horas de vida), deve-se suspeitar de oclusão intestinal (atrésia, mal-rotação, volvo intestinal), doença de Hirschsprung ou fibrose quística. Recorde-se que a eliminação de mecónio ocorre às $24 \mathrm{~h}$ em $90 \%$ dos recém-nascidos de termo e às $48 \mathrm{~h}$ em mais de $99 \%$.

A idade em que a criança adquiriu o controlo de esfíncteres e como decorreu o treino também é importante.

É fundamental a garantia de que a criança apresenta um crescimento estato-ponderal e um desenvolvimento psicomotor adequados. Emagrecimento ou má progressão ponderal são a favor de causa orgânica.

O conhecimento do tipo de alimentação é particularmente importante: aporte diário de água e fibra, idade de início e cronologia da diversificação alimentar, pela possibilidade de no lactente se tratar de uma obstipação secundária a doença celíaca ou alergia às proteínas do leite de vaca.

É importante questionar sobre antecedentes de infeções urinárias e/ou incontinência urinária.
Muitas crianças com obstipação e encoprese também têm enurese e por vezes refluxo vesico ureteral, que pode levar a infeções urinárias de repetição; comorbilidades frequentes mas que podem indicar causa orgânica. Por outro lado algumas doenças cursam com obstipação, nomeadamente, diabetes mellitus, hipotiroidismo, hiperparatiroidismo, paralisia cerebral e neurofibromatose. A realização de medicação crónica com anticolinérgicos, antiepiléticos, anti-inflamatórios não esteroides, suplementos de cálcio e ferro também pode estar na origem da obstipação.

Quanto aos antecedentes familiares, a existência de obstipação noutros elementos da família (particularmente na mãe) e de doenças como hipotiroidismo, doença celíaca e fibrose quística são relevantes.

Por último, não esquecer a história psicossocial, designadamente, alterações no ambiente familiar e/ou escolar, comportamentos de oposição, viagens recentes, suspeita de abuso sexual, entre outros.

O exame objetivo deve ser completo. Distensão abdominal e/ou pregas de desnutrição à inspeção, bem como uma cicatriz de cirurgia prévia, representam sinais de alarme. A inspeção peri-anal revela frequentemente fezes e pode mostrar achados que justifiquem a retenção fecal, como fissura anal (localização habitual às 6/12h) e anusite infeciosa. Constituem sinais de alarme à inspeção peri-anal: ânus anterior, prolapso retal (obstipação grave, fibrose quística), fístula ou abcesso (doença de Crohn). A inspeção da região sacro-coccígea visa excluir lesões sugestivas de 
etiologia neurológica (solução de continuidade, massa, tufo de pêlos).

A palpação abdominal de crianças com obstipação revela habitualmente fecalomas na fossa ilíaca esquerda e cordão cólico nas impactações fecais mais graves.

A realização de toque retal numa primeira abordagem é controversa. Este procedimento adquire maior importância na presença de sinais de alarme, na suspeita de doença orgânica ou nos casos refratários à terapêutica, após explicação à criança e aos pais do seu objetivo. O toque retal permite avaliar a sensibilidade anal, o tónus esfincteriano, o diâmetro retal e a presença e o tipo de fezes na ampola. Na obstipação funcional é comum o tónus esfincteriano estar ligeiramente diminuído, o reto encontrar-se distendido e haver um grande volume de fezes duras na ampola retal. O toque retal sugere doença de Hirschsprung perante os seguintes achados: tónus muito aumentado, ausência de fezes na ampola retal com palpação abdominal de fecalomas, saída explosiva de fezes líquidas e/ou gás após retirada do dedo do reto.

O exame neurológico é fundamental. A sensibilidade, a força muscular e os reflexos dos membros inferiores estão alterados nas patologias com envolvimento das raízes sagradas.

\subsubsection{Exames complementares de diagnóstico}

A história clínica completa permite na grande maioria dos casos excluir causas orgânicas, dispensando a necessidade de qualquer meio complementar de diagnóstico.
A realização de uma radiografia simples do abdómen para determinar a presença de distensão e/ou preenchimento por fezes do cólon é controversa, uma vez que não existe correlação entre a imagem radiológica de acumulação de fezes e a clínica de obstipação. Contudo, alguns autores consideram a possibilidade da sua realização perante dúvida diagnóstica nas crianças obesas, devido à espessura do panículo adiposo; nas crianças relutantes à realização do toque retal (fatores psicológicos, abuso sexual, ...) e ainda quando a história clínica é sugestiva, mas não existem fezes palpáveis ao toque retal.

No caso de atraso na eliminação de mecónio, é importante excluir doença de Hirschsprung e fibrose quística. Na suspeita de outra patologia orgânica, a principal investigação inclui rastreio de doença celíaca e pesquisa de causas endócrino-metabólicas com doseamento sérico de TSH, T4 livre, $\mathrm{Ca}^{2+}$ e $\mathrm{K}+$. Um exame imagiológico da coluna lombossagrada está indicado se houver evidência de lesão medular.

\subsubsection{Tratamento}

Os três grandes objetivos do tratamento são: desimpactação fecal, prevenção da reacumulação de fezes e criação de hábitos intestinais regulares. Para atingir estes objetivos recorre-se a três modalidades complementares: educação, dieta e fármacos.

A educação é uma das fases mais importantes do tratamento da obstipação. Consiste em desmistificar esta patologia, explicando aos pais e, sempre que possível, à criança a sua fisiopatologia, levando-os a compreender que a incontinência fecal é involuntária. O treino 
intestinal diário consiste em ensinar a criança a defecar num horário regular, cinco a dez minutos após duas ou três refeições, aproveitando o reflexo gastro-cólico, relaxadamente e com apoio adequado dos pés. Esta medida é importante para horizontalizar o ângulo ano-retal, facilitando assim a dejeção.

A criança mais velha deve ser incentivada a registar num diário as suas dejeções e eventuais episódios de incontinência fecal. Este registo envolve ativamente a criança no processo terapêutico e permite melhor avaliação pelo médico na consulta subsequente.

O reforço positivo das dejeções em local apropriado é muito importante, sobretudo na criança que está a iniciar o treino da defecação.

A alimentação destas crianças deve ser saudável, rica em fibras solúveis e com ingestão adequada de líquidos. Contudo, o aumento do seu consumo para além da dose diária recomendada não está comprovadamente associado a maior eficácia do tratamento.

Em relação à terapêutica farmacológica, a desimpactação fecal é normalmente a primeira medida necessária antes do início da terapêutica de manutenção, sendo mandatória nos casos em que existe incontinência fecal. A impactação fecal é então definida pela presença de um ou mais dos seguintes aspetos: incontinência fecal, massa dura localizada nos quadrantes inferiores do abdómen durante o exame físico, ampola retal dilatada com abundante quantidade de fezes no toque retal e quantidade excessiva de fezes no cólon identificada pela radiografia abdominal, nos casos em que está indicada a sua realização.
A desimpactação fecal deve ser realizada preferencialmente por via oral, recorrendo em primeira linha aos laxantes osmóticos. Os laxantes estimulantes podem ser utilizados nos casos refratários ou nos casos de intolerância aos laxantes osmóticos.

Os laxantes osmóticos orais tais como a lactulose, o macrogol e o hidróxido de magnésio, têm como principal função aumentar a concentração de água nas fezes, diminuindo a sua consistência e facilitando a sua eliminação. Não provocam dependência.

Os laxantes estimulantes orais, como o bisacodilo e o senne, têm como mecanismo de ação o aumento da peristalse intestinal no íleon terminal e no cólon, diminuindo a absorção e aumentando a secreção de água e eletrólitos pela mucosa do cólon. Os seus principais efeitos adversos são cólicas, melanosis coli reversível e possibilidade de dependência em uso prolongado.

A desimpactação exclusiva por via retal deve ser evitada. O uso de microclisteres, supositórios e enemas são procedimentos relativamente invasivos, associados a maior risco de iatrogenia e dano psicológico. Têm como vantagem permitir uma dejeção num tempo e espaço adequados, sendo particularmente úteis nas impactações agudas observadas nos serviços de urgência.

A terapêutica de manutenção visa evitar a reacumulação de fezes e o reaparecimento de comportamentos de retenção; consiste no uso diário de laxantes osmóticos como terapêutica de primeira linha. O período mínimo de tratamento é de dois a três meses, tempo necessário 
para o reto readquirir o seu diâmetro e sensibilidade habituais. A dose ideal é a que permite a passagem, pelo menos uma vez por dia, de fezes de consistência normal, sem efeitos secundários relacionados com a dose de fármaco utilizada. Os laxantes estimulantes não são habitualmente usados como terapêutica diária, contudo podem ser utilizados de forma intermitente nos casos de obstipação grave e refratária, preferencialmente sob a supervisão de gastroenterologista pediátrico.

Deve ser explicado aos pais que o processo de tratamento é lento (duração habitual superior a seis meses), caracterizando-se por avanços e recuos naturais. Tentativas precoces de suspensão farmacológica associam-se a maior taxa de recidiva.

\section{Outros tratamentos}

A maioria das crianças e adolescentes com obstipação são tratados com as medidas educacionais, correção do tipo de alimentação e a terapêutica convencional previamente descritas. No entanto, nalgumas crianças o tratamento médico é prolongado e pouco eficaz, podendo ser necessário intervenção em regime de internamento. Casos refratários poderão ser candidatos a outras modalidades terapêuticas.

\subsubsection{Prognóstico}

A obstipação e a incontinência fecal, apesar de "benignas" na sua etiopatogenia e potencialmente tratáveis, estão associadas a compromisso da qualidade de vida e repercussões sociais importantes.
Mais de metade dos indivíduos seguidos em hospitais terciários ficam assintomáticos após um ano de tratamento e cerca de 65 a 70\% depois de dois. No entanto, mesmo sob tratamento farmacológico e comportamental inicial intensivo, cerca de um terço das crianças irá manter obstipação após cinco anos de seguimento e algumas até após a adolescência. Outro dado importante é que aproximadamente metade das crianças tratadas tem uma recidiva nos cinco anos seguintes. O aparecimento de obstipação antes dos 12 meses e a presença de incontinência fecal são indicadores de pior prognóstico.

\subsubsection{Factos a reter}

- A obstipação é um diagnóstico com elevada prevalência em Pediatria.

- Após o período neonatal 90 a 95\% das obstipações são funcionais.

- Em 90\% dos casos a encoprese é secundária à obstipação.

- A história clínica completa é fundamental para o diagnóstico e identificação de sinais de alarme.

- Raramente são necessários exames complementares de diagnóstico.

- O tratamento deve ser precoce e tem como objetivo a desimpactação, a prevenção da reacumulação fecal e a criação de hábitos intestinais regulares.

- A educação da criança e da família, uma alimentação saudável e o uso de laxantes osmóticos constituem os três pilares do tratamento.

- O prognóstico depende da eficácia da intervenção. 


\subsection{ENURESE}

\subsubsection{Definições e epidemiologia}

À semelhança da obstipação, a enurese é também um motivo frequente de consulta em Pediatria.

A criança geralmente adquire o controlo do esfíncter vesical entre os três e os seis anos, inicialmente durante o dia e posteriormente à noite. Classicamente consideram-se os cinco anos como a idade expectável para a aquisição da continência urinária noturna.

A International Children's Continence Society define enurese ou enurese noturna como incontinência urinária intermitente durante o sono, numa criança com pelo menos cinco anos. Segundo os critérios da DMS-5 esta emissão involuntária e repetida de urina durante o sono, deve ocorrer pelo menos duas vezes por semana durante três meses consecutivos ou causar ansiedade/compromisso social, não deve ser atribuível a efeito secundário de fármaco (i.e. diuréticos, anti psicóticos) ou a doença (i.e. diabetes, espinha bífida, epilepsia) e a criança deverá ter uma idade cronológica ou mental igual ou superior a cinco anos.

A enurese pode ser classificada como primária ou secundária e monossintomática ou não monossintomática:

- Enurese primária: quando a criança não teve um período consecutivo de noites secas igual ou superior a seis meses.

- Enurese secundária: quando se verifica a instalação novamente de noites molhadas após um período de pelo menos seis meses de continência noturna. Está muitas vezes associada a acontecimentos ansiogénicos como nascimento de um irmão, morte de um familiar próximo, divórcio dos pais, mudança de escola, entre outros.

- Enurese monossintomática: enurese numa criança sem qualquer outro sintoma das vias urinárias inferiores e sem história de disfunção vesical.

- Enurese não monossintomática: enurese numa criança com sintomas das vias urinárias inferiores (aumento/diminuição da frequência miccional, incontinência diurna, urgência ou hesitação miccional, polaquiúria, jacto urinário fraco, manobras de retenção, sensação de esvaziamento incompleto, disúria).

Nesta lição iremos abordar apenas a enurese noturna monossintomática por ser a forma de apresentação mais frequente.

A prevalência da enurese depende dos critérios de diagnóstico utilizados. Estima-se que cerca de $10 \%$ das crianças de sete anos, molham regularmente a cama. Embora a enurese tenda a desaparecer naturalmente, com uma taxa de remissão espontânea anual de 15\%, cerca de 1-2\% permanecerão enuréticos até à idade adulta.

Existe um predomínio no género masculino $(1,5-2: 1)$.

Fatores genéticos determinam não só a probabilidade de uma criança ter enurese (44\% se um dos pais foi enurético, $77 \%$ se foram os dois) mas também a idade da resolução do quadro. 


\begin{tabular}{|ll|}
\hline Mecanismo & Fisiopatologia \\
\hline $\begin{array}{l}\text { Défice noturno de } \\
\text { vasopressina }\end{array}$ & Poliúria noturna \\
\hline $\begin{array}{l}\text { Hiperatividade } \\
\text { noturna do detrussor }\end{array}$ & $\begin{array}{l}\downarrow \text { Capacidade } \\
\text { vesical noturna }\end{array}$ \\
\hline $\begin{array}{l}\text { Limiar elevado } \\
\text { de despertar }\end{array}$ & $\begin{array}{l}\text { Não acordam com a } \\
\text { distensão vesical ou com } \\
\text { a contração do detrussor }\end{array}$ \\
\hline
\end{tabular}

Quadro 2. Mecanismos patogénicos envolvidos na enurese monossintomática.

\subsubsection{Fisiopatologia}

A enurese monossintomática é quase sempre uma situação benigna, explicada por um ou mais dos mecanismos fisiopatogénicos listados no quadro 2.

Raramente a enurese pode ser um sintoma de uma doença orgânica tal como acontece na infeção urinária, nas malformações nefrourológicas, na insuficiência renal, na hipercalciúria, na diabetes insípida central ou nefrogénica, na diabetes mellitus, em doenças do sistema nervoso central, doenças neurológicas lombossagradas ou epilepsia.

\subsubsection{Diagnóstico}

Mais uma vez é fundamental realizar uma história clinica completa e detalhada. Esta permitir-nos-á fazer o diagnóstico de enurese e identificar sinais de alarme.

$\mathrm{Na}$ anamnese deve ser recolhida informação que permita classificar a enurese como continua ou intermitente, primária ou secundária, monossintomática ou não. É então necessário saber a frequência de noites molhadas, o número de episódios/noite e o horário em que ocorrem, a facilidade para despertar com episódios enuréticos ou outros estímulos. A quantidade, o horário e o tipo de líquidos ingeridos também é importante saber. Por exemplo, bebidas com cafeína podem ter um efeito diurético e causar hiperatividade da bexiga. A presença de polidipsia e/ou polifagia, de alterações do jato urinário, do volume de urina ou da capacidade de retenção; a presença de incontinência urinária diurna, de disúria, polaquiúria ou urgência miccional; hematúria ou história de litíase; obstipação e/ou encoprese; cefaleias, convulsões ou ausências, podem sugerir existência de patologia orgânica.

Devem ser identificados fatores predisponentes como antecedentes familiares de enurese, características da família, conflitos familiares, nascimento de um irmão ou morte de um familiar, mudança de escola ou residência, internamento recente, entre outros.

Deve ser questionado se já foi realizada alguma investigação e/ou terapêutica e os respetivos resultados.

É também necessário avaliar a existência de comorbilidades que podem ter um papel importante na patogénese e serem responsáveis por ausência de resposta à terapêutica instituída. São exemplo: a obstipação, presente em cerca de um terço dos casos, infeções urinárias de repetição (indicador de disfunção vesical), patologia do neurodesenvolvimento ou psiquiátrica como perturbação de hiperatividade e défice de atenção, ansiedade, depressão; distúrbios do sono como o síndrome de apneia obstrutiva do sono e parassónias. 
Por último é fundamental avaliar como é que a criança e família lidam com este problema (indiferença? vergonha? culpa? castigos? prémios pelas noites secas?), a perturbação que causa na qualidade de vida e no sono de ambos e a atual motivação de todos.

O exame objetivo da criança enurética é habitualmente normal. No entanto este deve ser minucioso para identificar alterações anatómicas ou neurológicas que possam ser responsáveis pela enurese. Deve-se prestar especial atenção à avaliação do crescimento, da tensão arterial, dos genitais, da região lombossagrada e efetuar um exame neurológico. Um atraso estatural pode acompanhar uma insuficiência renal crónica ou outras doenças nefrourológicas que cursam com poliúria. Muitas nefro e uropatias acompanham-se de hipertensão arterial. Alterações dos genitais e da região lombossagrada podem associar-se a malformações urológicas. No abdómen, a palpação de globo vesical pode indicar obstrução e a presença de fita cólica, obstipação. Alterações da marcha, dos reflexos osteotendinosos, da força ou tónus muscular dos membros inferiores, da sensibilidade perineal ou do tónus do esfíncter anal sugerem patologia neurológica.

\subsubsection{Exames complementares de diagnóstico}

Na avaliação inicial de uma enurese noturna primária monossintomática o único exame necessário é uma análise sumaria de urina ou um teste rápido de urina (tira-teste). Este exame simples, barato e universalmente disponível permite excluir algumas doenças que podem cursar com enurese. Assim é importante analisar a densidade urinária (diabetes insípida), glicosúria e cetonúria (diabetes melitus), leucocitúria e presença de nitritos (infeção urinária), hematúria e proteinúria (doença renal).

Perante uma enurese não monossintomática, na suspeita de doença orgânica, ou na ausência de resposta ao tratamento, outros exames poderão ser necessários e deverão ser solicitados caso-a- caso: sumária de urina com sedimento urinário e urocultura, ecografia reno-vesical, estudo urodinâmico, entre outros.

\subsubsection{Tratamento}

A intervenção deverá iniciar-se pela educação. É necessário explicar à criança e à família o normal funcionamento do trato urinário inferior e a patogenia da enurese, salientado que se trata de um problema comum que afeta muitas crianças e que ninguém é culpado, pelo que a criança não deve ser castigada.

Deverão então ser aconselhadas medidas comportamentais: assegurar a ingestão adequada de líquidos durante o dia, limitar o seu consumo no final do dia e restrição total uma hora antes de deitar; evitar bebidas com cafeína, alimentos com elevado teor proteico ou sal; incentivar micções regulares durante o dia (quatro a sete/dia) e a última mesmo antes de deitar. Solicitar o registo das noites secas/ molhadas num calendário. Esta medida tem um efeito psicoterapêutico por si só e permite avaliar de forma mais objetiva a resposta às medidas instituídas. Está desaconselhado o uso de fralda e não é necessário acordar a criança durante a noite para urinar. 
Alguns casos resolvem apenas com esta abordagem. Nesta fase o médico e/ou a família poderão decidir não progredir na intervenção.

Para além destas medidas gerais, que devem ser instituídas a toda a criança enurética, existem duas opções terapêuticas de primeira linha: o alarme e a administração de desmopressina.

Antes dos sete anos não é previsível uma taxa de resposta ao tratamento superior à taxa de remissão espontânea da enurese. Contudo este pode ser iniciado antes, se o impacte da enurese na criança ou na família for negativo.

Nos casos em que também existem sintomas diurnos ou obstipação, estes devem ser tratados em primeiro lugar pois poderão ser responsáveis pela falência do tratamento.

Alarme: dispositivo que emite um sinal, habitualmente sonoro, quando o sensor colocado na roupa interior, humedece. A criança deve acordar com o alarme, ir à sanita terminar a micção, ajudar na mudança de lençóis e voltar a aplicar o alarme. Este processo tem que ser monitorizado por um adulto para garantir que a criança cumpra todos estes passos e simplesmente não desligue o alarme e volte a adormecer. Pretende-se com este dispositivo criar uma resposta condicionada à repleção vesical, sendo necessário o seu uso diário. Segundo alguns autores, o alarme também pode aumentar a capacidade vesical durante a noite. Por requerer o envolvimento da criança e da família, está apenas indicado quando ambos estejam motivados. É uma boa opção para crianças sem poliúria e com capacidade vesical reduzida.
É a estratégia mais eficaz no tratamento de enurese com uma taxa de sucesso estimada em 66 a $70 \%$.

Desmopressina: análogo sintético da vasopressina, diminui a produção noturna de urina e por isso é particularmente útil nas crianças com poliúria noturna e capacidade vesical normal. Está também indicada quando não há motivação para a prescrição do alarme ou este não foi eficaz. Cerca de um terço das crianças tem resposta completa e $40 \%$ parcial. O potencial de cura é baixo, com uma taxa de recaída elevada. Consoante a formulação utilizada deverá ser administrado meia a uma hora antes da última micção, ao deitar. É um fármaco seguro, com poucos efeitos secundários, mas se a criança ingerir uma quantidade excessiva de líquidos, há risco de intoxicação hídrica, hiponatrémia e convulsões. Por este motivo recomenda-se reduzir a ingestão de líquidos à noite e a sua restrição uma hora antes da administração da desmopressina e nas oito horas seguintes.

A escolha da terapêutica deve ser discutida com a família tendo em conta o mecanismo fisiopatogénico subjacente, as características da criança e a motivação familiar. Perante uma criança com poliúria noturna associada a capacidade vesical normal a desmopressina será a melhor opção. Nos outros casos deve-se recomendar o alarme. Na ausência de resposta a um dos tratamentos deve ser oferecido o outro ou até a sua associação. Se mesmo assim mantiver enurese é necessário verificar se o tratamento foi feito corretamente, se não se trata de enurese não monossintomática, que requer outro tipo de intervenção; se existe alguma comorbilidade como 
obstipação que deverá ser tratada. Nesta fase, se ainda não foi feito, é necessário um diário miccional e pode estar indicada investigação adicional.

O passo terapêutico seguinte será a prescrição de um anticolinérgico (terapêutica de segunda linha). O fármaco mais utilizado é a oxibutinina, que atua diminuindo a atividade do detrussor e aumentando a capacidade vesical. É particularmente útil na enurese não monossintomática mas pode ser usada na enurese noturna com capacidade funcional reduzida, nomeadamente em associação à desmopressina.

A imipramina, um antidepressivo tricíclico, antigamente muito usada no tratamento da enurese constitui atualmente uma opção de terceira linha, a ser utilizada apenas em centros diferenciados, tendo em conta o seu potencial efeito cardiotóxico, podendo ser fatal em caso de intoxicação.

Eventualmente antes de iniciar o tratamento ou sempre que falhar a primeira opção é útil solicitar aos pais e à criança o registo de dados objetivos num diário miccional. Durante pelo menos dois dias deve ser contabilizado o volume das micções e de líquidos ingeridos e durante uma semana registar os episódios de enurese (com determinação do volume de urina perdido), de incontinência urinária diurna, eventuais sintomas das vias urinárias inferiores e hábitos intestinais.

Os diários fornecem dados objetivos, ajudam a identificar crianças com enurese não monossintomática ou que necessitam de investigação (por exemplo com polidipsia), o mecanismo patogénico preponderante (capacidade vesical diminuída ou poliúria noturna) e assim escolher o melhor tratamento a instituir. Permitem ainda identificar famílias pouco motivadas.

Avaliação e orientação das crianças com enurese secundária devem seguir esta mesma abordagem, tentando identificar e se possível orientar o fator desencadeante.

\subsubsection{Prognóstico}

Trata-se habitualmente de uma situação benigna, embora uma proporção significativa continue a molhar a cama durante a adolescência e alguns até à idade adulta. Este facto pode ter um impacte negativo considerável na criança/ adolescente e na sua família, tornando nestes casos o tratamento mandatório.

O efeito negativo depende da limitação que causa nas atividades do dia-a-dia (por exemplo ir dormir a casa de um amigo, ir acampar), da autoestima da criança, do grau de ostracismo por parte dos colegas e da forma como os pais ou cuidadores lidam com esta situação.

\subsubsection{Factos a reter}

- A enurese é um problema frequente em idade pediátrica.

- Embora habitualmente benigna, pode causar alterações importantes na auto-estima da criança e na dinâmica familiar.

- Os três mecanismos patogénicos envolvidos são a existência de poliúria noturna, hiperatividade do músculo detrussor e um limiar de despertar aumentado.

- Na avaliação inicial de uma criança com enurese monossintomática recomenda-se 
uma história clínica dirigida e completa e uma análise sumária de urina ou tira-teste urinária.

- A intervenção inicial passa por estabelecer hábitos miccionais e de ingestão hídrica adequados.

- O alarme e a desmopressina são os tratamentos de primeira linha. A escolha entre eles depende do mecanismo patogénico predominante e do grau de motivação familiar.

\section{Leitura complementar}

Roda J, Rubino G, Lapa P, Oliva M. Obstipação e Incontinência Fecal na Criança. Saúde Infantil 2012; 34(1): 25-30.

Neveus T, Eggert P, Evans J, et al. Evaluation of and treatment for monosymptomatic enuresis: a standardization document from the International Children's Continence Society. J Urol 2010;183(2): 441-447.

Tabbers MM, DiLorenzo C, Berger MY, et al. Evaluation and Treatment of Functional Constipation in Infants and Children: Evidence-Based Recommendations from ESPGHAN and NASPGHAN. JPGN 2014;58:258-274.

Benninga MA, Nurko S, Faure C, et al. Childhood Functional Gastrointestinal Disorders:Neonate/Toddler. Gastroenterology 2016:1443-1455.

Hyman JS, Di Lorenzo C, Saps M, et al. Childhood Functional Gastrointestinal Disorders:Child/Adolescents. Gastroenterology 2016;150:1456-1468.

Vande Walle J, Rittig S, Bauer S, et al. Practical consensus guidelines for the management of enuresis. Eur $J$ Pediatr 2012;171(6): 971-983. 